\title{
The Effect of Professional Partnership on the Development of a Mutual-help Organization
}

\author{
Deborah A. Salem - Thomas M. Reischl • \\ Katie W. Randall
}

Published online: 31 July 2008

(C) Springer Science+Business Media, LLC 2008

\begin{abstract}
The effects of partnership between Schizophrenics Anonymous (SA, a mutual-help organization) and the Mental Health Association in Michigan (MHAM, a professionally staffed advocacy organization) on SA's growth and development were explored. Following the initiation of a formal partnership, SA groups were more available throughout the state, more likely to be associated with formal mental health settings, and less likely to have leaders who had been participants in other SA groups. Groups with consumer leaders had significantly greater longevity than groups with professional leaders. Changes in the organizational structure and process of SA were also identified. SA leaders reported that SA moved from a collective to a more bureaucratic structure. As a result, there was greater consistency, administrative capacity, and response capacity. This enhanced capacity came with costs reported by SA leaders. The leadership role of SA members became less defined. SA members expressed concerns about the more hierarchical structure of SA's organization, decreased consumer control, increased professional involvement in SA, and an excessive focus on group development as opposed to group maintenance. Mental
\end{abstract}

D. A. Salem ( $\square)$

Department of Psychology, Michigan State University, 127A

Psychology Building, East Lansing, MI 48824-1116, USA

e-mail:salem@msu.edu

T. M. Reischl

School of Public Health, University of Michigan, Ann Arbor, MI, USA

e-mail: reischl@umich.edu

K. W. Randall

Washington State Mental Health Division, Washington, DC, USA
Health Association in Michigan staff reported that MHAM was also impacted by the partnership, both with regard to internal functioning and external perception. Implications for effective partnerships between mutual-help and professional organizations are discussed.

Keywords Mutual-help · Self-help · Mental health · Professional involvement $\cdot$ Collaboration

There has been considerable debate within the mutual-help literature as to costs and benefits of professional involvement with mutual-help groups and organizations. Many writers have noted a natural tension between professionals and mutual-help organizations resulting from differences in power (Powell and Cameron 1991; Zinman 1987), helping relationships (Medvene 1984), and ideologies (Gartner 1997; Schubert and Borkman 1991). Some have warned these tensions may result in antagonistic relationships or that collaboration with professionals may undermine the essential consumer-run elements of mutual-help (e.g., Chamberlin 1990; Emerick 1991; Zinman 1987). Others have argued that in spite of these tensions, collaborations between professionals and mutual-help groups can be mutually beneficial (Ben-Ari 2002; Comstock and Mohamoud 1990; Kurtz 1990; Olson et al. 2005; Powell and Cameron 1991; Stewart 1990; Yoak and Chessler 1985).

Despite this debate, the involvement of professionals in mutual-help groups and organizations has increased (BenAri 2002; Lotery and Jacobs 1994; Riessman and Carroll 1995; Shepherd et al. 1999). The debate on whether professionals should be involved in mutual-help has been replaced by a focus on the nature and effects of professional involvement (Ben-Ari 2002). Scholars have focused 
on professionals' roles in mutual-help groups (Kurtz 1990; Shepherd et al. 1999; Stewart et al. 1994; Toseland and Hacker 1982), professionals' views of mutual-help groups (Kurtz et al. 1987; Meissen et al. 1991; Stewart et al. 1994), mutual-help members' views of professional involvement (Lotery and Jacobs 1994; Stewart et al. 1994), and mechanisms of successful collaboration (Chinman et al. 2002; Gartner 1997; Olson et al. 2005; Toseland and Hacker 1982)

To date most of the published literature on professional/ mutual-help interaction has focused on the involvement of individual professionals in groups (Hasenfeld and Gidron 1993). These studies have found clear differences between mutual-help groups that do and do not have professional involvement with regard to group process (Cherniss and Cherniss 1987; Toro et al. 1988), activities (Shepherd et al. 1999; Yoak and Chessler 1985), associations with other organizations (Shepherd et al. 1999), and survival (Maton et al. 1989).

Less attention has been focused on the growing development of cooperative relationships between mutual-help organizations and more formal organizations (e.g., social service agencies, advocacy organizations, HMOs). Mutualhelp organizations have developed more direct and sustained collaborations with professionally led organizations, ranging from limited contacts (e.g., referrals) to joint operating arrangements. Such collaborations have helped mutual-help organizations gain resources, visibility, and organizational capacity.

These collaborations have also carried the risks of cooptation and other organizational pressures (Borkman 1999; Gidron and Hasenfeld 1994; Hasenfeld and Gidron 1993). Organizational theories have directed our attention to how the demands and pressures in the organizational environment can influence the values, structures, practices, and life course of organizations (Gidron and Hasenfeld 1994). Institutional theorists have argued that in order to survive, organizations within the same organizational sector come to look and behave like other organizations in that sector (DiMaggio and Powell 1983; Meyer and Rowan 1977). This increases their legitimacy and access to resources.

Drawing from institutional theory, Salem (1996) argued that as mutual-help organizations interact closely with organizations in other sectors (e.g., mental health), they are subject to the same institutional pressures and may experience significant changes in their structures, ideologies, and activities. Others have suggested that simply managing a cooperative relationship requires a structural predictability and stability that is not typical of mutual-help organizations (Gidron and Hasenfeld 1994). Bargal (1992) argued that, unlike more formal organizations, mutual-help organizations often aspire to remain forever at the collectivity stage of development, which is characterized by informal communication and structure.

Although interactions between mutual-help organizations and other organizations are increasing, we know little about how such collaborations develop or influence the ideology, growth, or structure of mutual-help organizations. The present study explores an evolving collaboration between a mutual-help organization, Schizophrenics Anonymous (SA) and the Mental Health Association in Michigan (MHAM), a not-for-profit, professionally run mental health advocacy organization that supported SA's development. Guided by institutional (Meyer and Rowan 1977) and resource dependence (Pfeffer and Salanick 1978) theories, we explored how increased collaboration with MHAM influenced SA's organizational growth and development. We examined SA's intended goals in developing this partnership of enhancing their organizational capacity in order to reach more individuals with schizophrenia. We also examined unintended consequences of the partnership, including: (a) increased interaction with the traditional mental health system, (b) changes in leadership development within SA, and (c) changes in SA's organizational structure. Finally, we explored whether there was a reciprocal influence of the partnership on the MHAM.

\section{Method}

This study was part of a larger evaluation study of the SA organization. It began at an important point in the relationship between SA and MHAM. Twelve years after the first SA group was founded, MHAM received a grant that allowed them to devote full-time equivalent staffing to assist SA with organizational expansion and development and to evaluate that effort. Our initial intention was to study the process and outcome of this expansion, focusing on the development of new SA groups in Michigan (USA). One year into the study, we became aware that as a result of working with MHAM, SA was changing their approach to expansion and that the newly funded expansion could be best understood in the context of the history of SA's development. The decision was made to collect retrospective data on SA's development during its first 11 years. Our qualitative/quantitative case study also followed SA's expansion and development prospectively for three additional years (Years 12-14). This allowed us to study a naturally evolving partnership and to compare the organization's growth and development before and after their more formal partnership with MHAM.

At the start of this project we had a seven-year history of research collaboration with SA focused on evaluation of SA's efforts to start groups in new settings and on understanding how SA helped its members. While SA leaders and the researchers worked together to develop evaluation 
questions and methods, the role of the research team was limited to evaluation of SA's and MHAH's efforts. All programmatic and expansion decisions were made and carried out by SA and MHAM.

\section{Describing the Organizational Development of SA}

Data describing the organizational development of SA came from four sources: (a) interviews with SA organizational leaders, (b) interviews with MHAM staff, (c) review of archival data, and (d) attendance at organizational meetings and events. The following four subsections describe these four data sources in more detail.

\section{Interviews with SA Organizational Leaders}

Based on our previous association with SA, we generated a list of SA members who we had observed to be involved in organizational development (e.g., regularly attended organizational leadership meetings, involved in organizational level decision making). Our list was confirmed by the leaders themselves when they independently identified the same four people as SA's primary leaders, or in their words- "Central SA leaders." 1 These leaders participated in two telephone interviews, a year apart. A fifth SA member, who was later hired by MHAM to work on SA expansion, was interviewed once. These semi-structured interviews focused on interviewees' roles as SA leaders and SA's organizational structure, leadership, and expansion efforts. All five also participated in more in-depth interviews regarding their personal experience in SA. Interviews were audio taped. All of the leaders were middle-aged and white. Three were female.

\section{Interviews with MHAM Staff}

Beginning in Year 6, one MHAM staff member took primary responsibility for working with SA on group and organizational development. Over a three-year period, he participated in 21 interviews regarding these efforts. The executive director of MHAM was also interviewed once regarding the history of the development of MHAM's relationship with SA. Both were white men with professional training. Neither was a mental health consumer.

\footnotetext{
${ }^{1}$ At this stage of SA's organizational development the term Central SA leader was used to refer to a self-identified group of SA leaders who formed the leadership core of SA. This was the group who saw themselves as responsible for SA's programmatic and organizational development. The term "Central SA" took on a different meaning later in SA's development, referring to SA's national leadership group.
}

\section{Archival Data}

SA literature (i.e., newsletters, correspondence, brochures, training manuals, grant proposals) was reviewed in order to better understand expansion and leadership support activities. All letters written by MHAM in response to inquiries for information about SA for Years 8 through 13 were coded for type of request (general information, interest in starting SA group) and recipient (consumer, family member, professional, organization).

\section{Attendance at Organizational Meetings and Events}

Over a three-year period, research team members attended and wrote field notes for organizational meetings and events related to $\mathrm{SA}$ expansion and development. We attended three annual conferences, an organizational planning retreat, 23 of 30 organizational leadership meetings, and SA community and conference presentations.

\section{Qualitative Analysis of Interview Data and Field Notes}

Interview transcripts were transcribed verbatim and checked for accuracy. Transcripts, interview notes, and field notes were then formatted and imported into NU*DIST, a computer software package for qualitative research. Inductive content analysis was used to identify underlying themes across participants (Patton 2002). One research team member, who was very familiar with the interviews and field notes, read each document and constructed a preliminary set of themes or categories. This involved categorizing or bringing together information units with similar content. A name was then assigned to each category and all subsequent units of information were then excluded or included in the category. The categories were then reviewed by two other research team members. Adjustments were made based on this review and the data was recoded to reflect these changes. Final codes and quotes were reviewed by the larger team. Findings were then authenticated in discussions with MHAM staff and SA leaders.

\section{Documenting Group Development}

To track development, we used archival documents that referenced the status of specific SA groups in Michigan (e.g., all SA newsletters) and interviewed SA organizational and group leaders and MHAM staff. From these sources, we recorded four variables reflecting each group's longevity and geographic location: start date, closing date, distance in miles from original SA group, and county. We also recorded two variables about the group's connection to 
the traditional mental health system: type of group leader ${ }^{2}$ (mental health consumer, professional service provider, or co-led by consumer and professional) and type of group setting where the group met [community non-service settings (e.g., community building, church); community-based mental health service settings (e.g., community mental health center, drop-in center); institutions (e.g., hospital, correctional institution)]. Finally, we recorded leader experience with a "Central SA group." Central SA group was a term used early in SA's development for groups led by one of SA's self-identified leadership core. The Central SA groups formed the core of the organization. Prior to formal leadership training initiated by MHAM, these groups served as the training ground for SA leaders.

Using all data sources, we verified that 64 SA groups had operated for some period of time during the 14 years after SA was founded. Forty-two groups were active during Years 12-14 when we conducted the study. Data for these 42 groups was collected from either the group's leader $(n=34)$ or from archival records that were then confirmed by one of SA's organizational leaders $(n=8)$. For 41 of these 42 groups, we obtained with confidence (verified by at least two sources of data) the start dates and closing dates within three months $(n=39)$ or within six months $(n=2)$. For one group, we could not identify type of group leader.

Data on the 22 groups that closed before our study began was collected retrospectively. For 18 groups, we verified (with at least two different sources of data) the group's start and closing dates within three months $(n=11)$ or within six months $(n=7)$. For one group we could not verify the closing date and for two groups we could not verify the start or closing dates. We were unable to verify the type of group setting for one group and the type of group leader for three groups. Due to missing data, sample sizes for different study questions varied between 56 and 60 groups.

\section{Results}

The results of this case study are organized to first describe the development of the partnership between SA and MHAM, based primarily on qualitative data. Next, we present quantitative data analyses comparing SA's group development and group survival before and after MHAM took on primary responsibility for SA's expansion. We then present qualitative data on SA's organizational development after the formalization of the partnership and on the reciprocal influence of SA on MHAM.

\footnotetext{
2 Professionals were used at times to start groups, with the goal of developing consumer leadership over time. For some this was part of paid employment at their service agency/institution; others volunteered their time. All consumer leaders were volunteers.
}

The Development of the SA-MHAM Partnership

The seed for a relationship between SA and MHAM was planted a year before the start of SA, when Joanne Verbanic $^{3}$ (SA's founder) became a volunteer for MHAM. She explained:

I knew what it was like to be...so sick and I knew what it was like to be well. I wanted to share that experience....I had no idea of starting a group. I thought I'd just stuff envelopes. After a few meetings [with the MHAM executive director]...I was asked to appear on [The Sally Jesse Raphael Show]....I went public to help erase the stigma.

Soon after "going public," Joanne decided to start a self-help group. Using her own money, she advertised in a local newspaper stating that she was starting a self-help group for persons with schizophrenia. Two people responded and the first meetings occurred around tables at a local restaurant and a public park. Even though Joanne had gone public with her illness, the group decided to maintain anonymity in the Alcoholics Anonymous tradition. They named the group Schizophrenics Anonymous. When the colder autumn weather came, the executive director of MHAM suggested that the group meet in the board room of the MHAM office on Sunday afternoons when the offices were closed. A member of the first group recalls:

The whole time, he was taking a real risk. He's giving us the keys to the building....Here we have, you know, 15, 20 people with this illness which has got a bad rep [reputation].

With the assistance of MHAM, Joanne publicized the group. She recruited a MHAM staff member to help her write a pamphlet and MHAM paid for the printing. Joanne used her own money to mail the pamphlets to all of the psychiatrists in the Detroit telephone book. She continued to speak publicly about schizophrenia and about the new SA group. Attendance at the SA meetings was sporadic during the first year but after several local TV appearances and newspaper articles featuring Joanne and the SA group, attendance grew and became more stable.

This first group remained the only SA group for two years. Driven by the desire to reach out to more people with schizophrenia, several members of this original group started new groups in nearby communities. During Years $3-5$, eight new SA groups were started, six of them by members of the first SA group.

\footnotetext{
3 With her permission, Joanne Verbanic is the only person identified by her real name. All other persons are identified with pseudonyms.
} 
In Year 5, MHAM provided financial support to produce a video about SA. As Joanne described, it was an important event in the development of SA's partnership with MHAM:

I asked [the MHAM executive director]...I was nervous...I said, "What would you think if I did a video and it cost $\$ 3,000$ ?" I wanted it professionally done... and he liked the idea....We had to prove to him that people with schizophrenia could have their own group....He was society, and most people in society think people with schizophrenia can't do anything. You know, they're vegetables. So he bought into the situation.

During these early years, SA was in what Quinn and Cameron (1983) identify as the entrepreneurial stage of organizational development, characterized by innovation, resource mobilization, lack of planning and coordination, power in the hands of a prime mover, and niche creation. Joanne, the prime mover, worked to make groups available to more people. As SA continued to grow and develop, it entered the collectivity stage, characterized by informal communication and structure, a sense of collectivity, investment of long hours, commitment, a sense of mission, and continued innovation (Quinn and Cameron 1983).

Joanne continued to lead the original group and became SA's primary organizational leader. As organizational needs arose, a larger leadership group began to form. Most of the other group leaders had stayed in regular contact with members of the original group. They began to hold periodic organizational leader meetings to discuss issues related to their SA groups and to collectively write the organization's first publication. They called these gatherings "group consciousness meetings." Some of the participants became SA's organizational leaders. Joanne recalled the development of this leadership group in spiritual terms:

You know how God works? People just come to your life...I believe in serendipity... Bill comes to a meeting, he hears about it. And Bill said, "When I came to SA...I knew this is where I belonged." I had no idea he had talents to write. And then Janine...said we need to, you know, we just had a mimeograph sheet of paper with the steps [SA's six-step program] on it. We needed to get a booklet or something....So I suggested to Bill and his eyes lit up....And so we met for eight months in group consciousness meetings every two weeks, and they weren't just leaders [SA members contributed as well].

Bill described the cooperation among SA members involved in these efforts:

A lot of people were involved. We met every two weeks... and [had] discussions. I would tape the discussions, take it home, and write drafts and Ted wrote some very important parts....And then...[we] would go back with what we had written. It was kind of a group process...there were a lot of people involved in the ideas....There was Missy and Jack and Ned, who isn't around anymore...about five or six people at [each] meeting

After finishing the SA booklet in 1988, Bill assumed the responsibility for editing a SA newsletter. Started as a single issue publication, with the approval of other members, Bill has continued to edit and write most of the copy for a newsletter that is published twice a year.

During this period MHAM had an informal, but supportive relationship with $\mathrm{SA}$. In addition to providing space for group meetings and social events, MHAM paid for the production of the SA literature and videos. As the publication projects became more involved, MHAM started donating small amounts of staff time to assist in these productions. Perhaps most importantly for SA's expansion, MHAM was positioned to provide members with opportunities to speak at public events and to the media.

These opportunities to publicize SA led to a pivotal event. In Year 5 an article on schizophrenia appeared in the popular magazine, Cosmopolitan, featuring SA's founder (Joanne) and her recovery story. It included a telephone number and address for contacting SA- the telephone number and address of MHAM. The article elicited a large number of calls and letters requesting information and support for starting SA groups.

Both MHAM and the SA leaders recognized the limits to SA's ability to respond to this sudden demand for information and assistance. Joanne requested that MHAM staff share the responsibility for developing new groups with SA. During this time, several decisions were made that shaped the partnership between SA and MHAM. First, SA would retain its independent status; it would not become one of MHAM's programs. Second, programmatic decisions would continue to be made by SA's founder and SA leaders. Mental Health Association in Michigan staff members, however, began to assist directly in responding to information requests and with the development of new groups and new leaders. While SA maintained its independence with regard to the content of its program, this marked the beginning of a more formal partnership between SA and MHAM that would influence the future development of SA.

Over time, MHAM's increased role created pressure to solicit external funding for the staff time, travel, and materials needed to assist SA. This funding, coupled with increased interest in SA from around the State, created an external pressure on SA and MHAM to focus on expansion. This focus was consistent with SA's mission to reach 
Table 1 The Association between MHAM external funding and involvement with SA and the development of SA groups in Michigan

\begin{tabular}{|c|c|c|c|c|c|}
\hline Year & $\begin{array}{l}\text { Total grant } \\
\text { amounts }\end{array}$ & Changes in MHAM's involvement with SA & $\begin{array}{l}\text { New } \\
\text { groups }\end{array}$ & $\begin{array}{l}\text { Closed } \\
\text { groups }\end{array}$ & $\begin{array}{l}\text { Ongoing } \\
\text { groups }^{\mathrm{a}}\end{array}$ \\
\hline 1 & & \multirow[t]{2}{*}{ First SA group starts meeting at MHAM office } & \multirow[t]{2}{*}{1} & & 1 \\
\hline 2 & & & & & 1 \\
\hline 3 & & Publishes SA pamphlet & 2 & & 3 \\
\hline 4 & & Publishes SA booklet & 4 & & 7 \\
\hline 5 & & Produces SA video presentation Fields Cosmopolitan article inquiries & 2 & & 9 \\
\hline $6^{\mathbf{b}}$ & $\$ 7,000$ & \multirow[t]{3}{*}{ Formal collaboration begins Part-time MHAM staff assigned to SA } & 5 & & 14 \\
\hline 7 & $\$ 7,000$ & & 3 & 3 & 14 \\
\hline 8 & $\$ 21,500$ & & 4 & 3 & 15 \\
\hline 9 & $\$ 39,866$ & MHAM staff time increased Convenes group consciousness meetings & 9 & 2 & 22 \\
\hline 10 & $\$ 41,624$ & \multirow[t]{2}{*}{ MHAM staff time increased to .50 FTE } & 4 & 3 & 23 \\
\hline 11 & $\$ 18,400$ & & 9 & $5^{\mathrm{c}}$ & 27 \\
\hline 12 & $\$ 97,605$ & $\begin{array}{l}\text { MHAM staff time increased to } 1.00 \mathrm{FTE}^{\mathrm{d}} \text { Hires SA member part-time } \\
\text { Starts hosting annual leadership conference }\end{array}$ & 7 & 3 & 33 \\
\hline 13 & $\$ 99,169$ & \multirow[t]{2}{*}{ Begins exploring national expansion strategies } & 7 & 6 & 32 \\
\hline \multirow[t]{2}{*}{14} & $\$ 98,592$ & & 3 & 10 & $25^{\mathrm{e}}$ \\
\hline & & Totals & 60 & 35 & \\
\hline
\end{tabular}

\footnotetext{
${ }^{a}$ A group was counted as ongoing if it met at any time during the year

${ }^{\mathrm{b}}$ Bold denotes start of more formal partnership

c One of the groups included in this total closed in either Year 10 or Year 11

d At this time MHAM staff start to focus on leadership support and development as well as expansion

${ }^{\mathrm{e}}$ Four of these groups closed at some point during this year
}

out to others (Schizophrenics Anonymous 1992) and SA welcomed MHAM's support securing funds for expansion. The decision to have MHAM become the fiduciary body for SA seemed a natural one, as they had grant writing ability, accounting, and administrative capacity that SA did not. The collaboration continued to grow after MHAM obtained external grants targeted to the expansion of SA groups throughout Michigan in Year 6. These grants allowed MHAM to devote more staff time to assisting SA in responding to requests for information and helping consumers and professionals start new SA groups (see Table 1).

Starting in Year 12, the Ethel and James Flinn Family Foundation awarded MHAM a three-year grant of nearly $\$ 300,000$ for the purpose of developing new groups throughout Michigan and building leadership in SA. The large amount of this award allowed MHAM to assign increased professional staff time, as well as part-time clerical support, to the development of SA. In addition to paying for MHAM staff time, MHAM was able to contract with SA leaders to provide part-time organizational development assistance. Finding SA leaders to serve in this role proved to be challenging, as it was somewhat inconsistent with their previous emphasis on volunteer leadership. Most preferred to maintain their status as volunteer group leaders.
Impact of the Partnership on Group Development

The influx of external funding created both the capacity and the demand to start more SA groups. This was accomplished by a shift in SA's approach to new group development. Prior to receiving external funding, SA had expanded primarily through a process of internal leadership development. As existing SA members developed leadership skills and a desire to reach out to others with schizophrenia, they started their own SA groups. With the increased involvement of MHAM, an expansion strategy was developed that was both more targeted and more reactive. Potential locations for new SA groups were identified either through the expression of outside interest or MHAM's targeting of geographic locations without an SA group. New leaders came primarily from outside of SA- consumers or professionals who had not attended SA groups before. They were supplied with information and training materials in order to start groups.

In partnership with MHAM, SA began a new period of rapid organizational expansion. Table 1 summarizes the number of new groups established in Michigan during each year, the number of groups that were closed during each year (a group was considered closed if it had no meetings during the entire year), and the number of ongoing or continuing SA 
Table 2 Comparison of SA groups started before and after formal collaboration a The first SA group met at the MHAM office and was excluded from this analysis. $* x<.05$, $* * p<.01$

\begin{tabular}{|c|c|c|c|}
\hline \multirow[t]{2}{*}{ Group variable } & \multicolumn{2}{|c|}{ SA groups started } & \multirow[t]{2}{*}{$\chi^{2}$ test $(d f)$} \\
\hline & $\begin{array}{l}\text { Before } \\
\text { collaboration }\end{array}$ & $\begin{array}{l}\text { After } \\
\text { collaboration }\end{array}$ & \\
\hline \multicolumn{4}{|l|}{ Proximity to first SA group/MHAM office ${ }^{a}$} \\
\hline Less than 25 miles & $6(75 \%)$ & $15(29 \%)$ & $6.27 *(d f=1)$ \\
\hline More than 25 miles & $2(25 \%)$ & $36(71 \%)$ & \\
\hline \multicolumn{4}{|l|}{ Type of group setting } \\
\hline Community (non-service) & $4(44 \%)$ & $6(12 \%)$ & $6.08^{*}(d f=2)$ \\
\hline Community-based mental health service & $4(44 \%)$ & $28(56 \%)$ & \\
\hline Institutional & $1(11 \%)$ & $16(32 \%)$ & \\
\hline \multicolumn{4}{|l|}{ Type of group leader } \\
\hline Consumer leader & $7(88 \%)$ & $29(60 \%)$ & $2.19(d f=1)$ \\
\hline Professional leader or co-leader & $1(12 \%)$ & $19(40 \%)$ & \\
\hline \multicolumn{4}{|l|}{ Group leader's association with Central SA groups } \\
\hline Former leader or member of a Central SA group & $7(78 \%)$ & $14(28 \%)$ & $8.24 * *(d f=1)$ \\
\hline Never member Central SA group & $2(12 \%)$ & $36(72 \%)$ & \\
\hline
\end{tabular}

groups. ${ }^{4}$ It is clear from the tabulation of new groups in Table 1 that increases in external funding and in the level of MHAM's involvement were associated with larger numbers of new SA groups established in Michigan. Following the start of the formal collaboration (Year 6), 51 new SA groups (with known start dates) were established. While the number of group closings increased over the years, the number of ongoing groups more than tripled during this period.

To understand the effect of the partnership, we conducted cross-tabulations comparing SA groups that were established before and after Year 6 on geographic expansion (distance in miles from original SA group and county), type of group setting, and type of group leader. Year 6 marked the start of the formal partnership between SA and MHAM, when MHAM first designated a portion of a staff member's time to work with SA and first received external grant funding to support this work. As seen in Table 2, SA and MHAM were successful in increasing the availability of SA groups throughout Michigan. Before Year 6 all but two of the new groups established were in close proximity (within 25 miles) to the first SA group. After Year 6, there was a statistically significant difference in the percentage of SA groups established more than 25 miles away from SA's first group (the MHAM office). Before Year 6, SA groups were held in only four counties. After Year 6, SA groups met in 25 Michigan counties.

While SA and MHAM were successful in spreading SA over a much broader geographic area, there were accompanying changes in the nature of the groups. There was a statistically significant difference in the type of group

\footnotetext{
${ }^{4}$ While the main focus of SA's expansion was in Michigan, between Years 6 and 14, SA and MHAM also responded to requests from outside Michigan. In the latter years of this study, an increasing amount of MHAM staff time was devoted to group development outside of Michigan.
}

settings where groups were established. Before Year 6, 44\% of the group meetings were held in community (non-service) settings. After Year 6, the percent of groups meeting in community (non-service) settings (e.g., community building, church) dropped to $12 \%$. The percent of groups meeting in community-based, mental health service settings (e.g., community mental health center, drop-in center) increased slightly and the percent of groups meeting in institutional settings (hospitals, correctional facilities) almost tripled.

While the increase of new SA groups in mental health treatment settings provided access to more persons with schizophrenia, it resulted in an increased involvement with mental health professionals. The number of groups that had a professional leader or co-leader went from $12 \%$ to $40 \%$. The chi-square test for this difference, however, was not statistically significant. The expansion into new geographic regions was also associated with starting more groups with leaders who had never attended a Central SA group. This was the primary leadership training ground prior to Year 6, when seven of the nine groups $(78 \%)$ had leaders who had attended or led one of the Central SA groups. After Year 6, significantly fewer $(28 \%)$ of the new groups had a leader with any experience with one of the Central SA groups.

\section{SA Group Survival Analysis}

Because over half of the Michigan SA groups eventually closed and because all of the closings occurred after Year 6, we conducted survival analyses to explore whether the partnership with MHAM and the increased use of professional leaders and professional service settings affected how long groups survived. Survival analysis can be used to model the timing of a discrete change. It can be used for predicting change events (i.e., group closing) even if the event has not 
yet occurred for a substantial number of groups (see Luke 1993). The dependent measure in the survival analysis was the amount of time between the start date and the closing date scaled in months. ${ }^{5}$ The predictor variables for these analyses included: whether the group start date was before or after MHAM increased its involvement in Year 6, type of group setting, and type of group leader. Group comparisons in survival were estimated using the Kaplan-Meier method and the Log Rank test of group differences (Kaplan and Meier 1958; Mantel 1966).

The range of survival times for the sample of 59 SA groups included in these analyses was two to 160 months. The median survival time was 34 months (95\% CI: 28.0 to 40.0). The survival function and hazard function curves revealed a high rate of group closings during their first three years and that groups lasting more than three years had a much slower rate of closings. The comparative survival analyses revealed a wide variability of the estimated median survival times. Groups that started before Year 6 had a longer median survival period $(m d n=48.0$ months; 95\% CI: 27.7 to 68.3 ) than groups started after year 6 ( $m d n=31$ months; $95 \% C I: 20.0$ to 42.1 ), but the confidence intervals were overlapping and the difference was not statistically significant (Log Rank $(1 d f)=1.97)$. Likewise, the median survival period for SA groups started in community (non-service) settings ( $m d n=24$ months; 95\% CI: 17.9 to 30.1 ) was shorter than for the SA groups started in community-based, mental health service settings ( $m d n=36$ months; $95 \%$ CI: 28.6 to 43.4 ) or institutional settings ( $m d n=34$ months; 95\% CI: 18.4 to 49.7 ), but the differences were not significant $(\log \operatorname{Rank}(2 d f)=.52)$. Only the comparison of SA groups led by consumers vs. groups with professional leadership revealed a statistically significant difference (Log Rank $(1 d f)=4.21)$. Groups led by a consumer were more likely to survive for longer periods of time ( $m d n=36$ months; 95\% CI: 21.6 to 50.5) than groups led or co-led by professionals ( $m d n=26$ months; 95\% CI: 8.5 to 43.4). The survival curves for the SA groups led by consumers and by professional leaders are illustrated in Fig. 1. The curves suggest that the group survival probabilities are similar for the first three years, but that consumer-led SA groups have a greater probability of surviving beyond three years.

\section{Impact of the Partnership on Organizational}

Development

The impact of the partnership on organizational development was assessed using qualitative methods. By Year 12,

\footnotetext{
5 For the groups that had not closed by the end of Year 14, the group survival time was the amount of time between the start date and the end of Year 14.
}

the organizational structure of SA had changed. Joanne Verbanic was still leading SA's first group and continued to be the most influential leader in SA. A professional MHAM staff member was working full-time on SA's development, however, and had taken over much of the leadership responsibility for the SA organization. The MHAM office received and responded to all inquiries about starting SA groups. Efforts to generate funding, initiate new groups, and support existing leaders were now initiated from MHAM. In essence, while the SA members continued to control the SA program (i.e., the structure and content of the meetings), MHAM was now responsible for the administration of SA's organizational development.

While SA members and leaders still had an important voice in the organization, the nature of their contribution began to change. The "group consciousness meeting" became the primary setting for member input and involvement. At that time, the meetings occurred nearly every month and were facilitated by the MHAM staff member. In addition, MHAM contracted with a few SA leaders to assist the MHAM staff with organizational development. At this point SA could be described as moving into the life cycle stage of formalization and control (Quinn and Cameron 1983). This stage is characterized by the development of a stable structure and the formalization and institutionalization of rules and procedures. In our coding we identified five themes that are consistent with this stage: (a) increased control in the hands of one individual, (b) a more bureaucratic structure, (c) greater consistency, (d) greater administrative capacity, and (e) greater response capacity.

All of the SA organizational leaders noted that as a result of the partnership between SA and MHAM, there was increased control in the hands of one individual, the MHAM staff member. One described him as "the most influential person...the hub of SA... the leader, who works with Joanne and Bill." Another said, "He is our unity and strength. He keeps it together. We look to him for support....He keeps it all organized."

SA also developed a more bureaucratic structure, described by one leader like a business:

[The MHAM staff member] would be the chief administrative officer, Joanne would be the chief executive officer and primary decision maker, Wendy would be like the executive assistant or the chairman of the board of directors - whoever it is who does the administrative work and would answer to [MHAM staff member]. The Group Consciousness Meeting would be like the board of directors.

This new structure had a variety of influences on the SA organization. Leaders viewed some of the changes very positively. The partnership provided SA with greater 
Fig. 1 Survival curves for SA groups led by consumers or by professionals

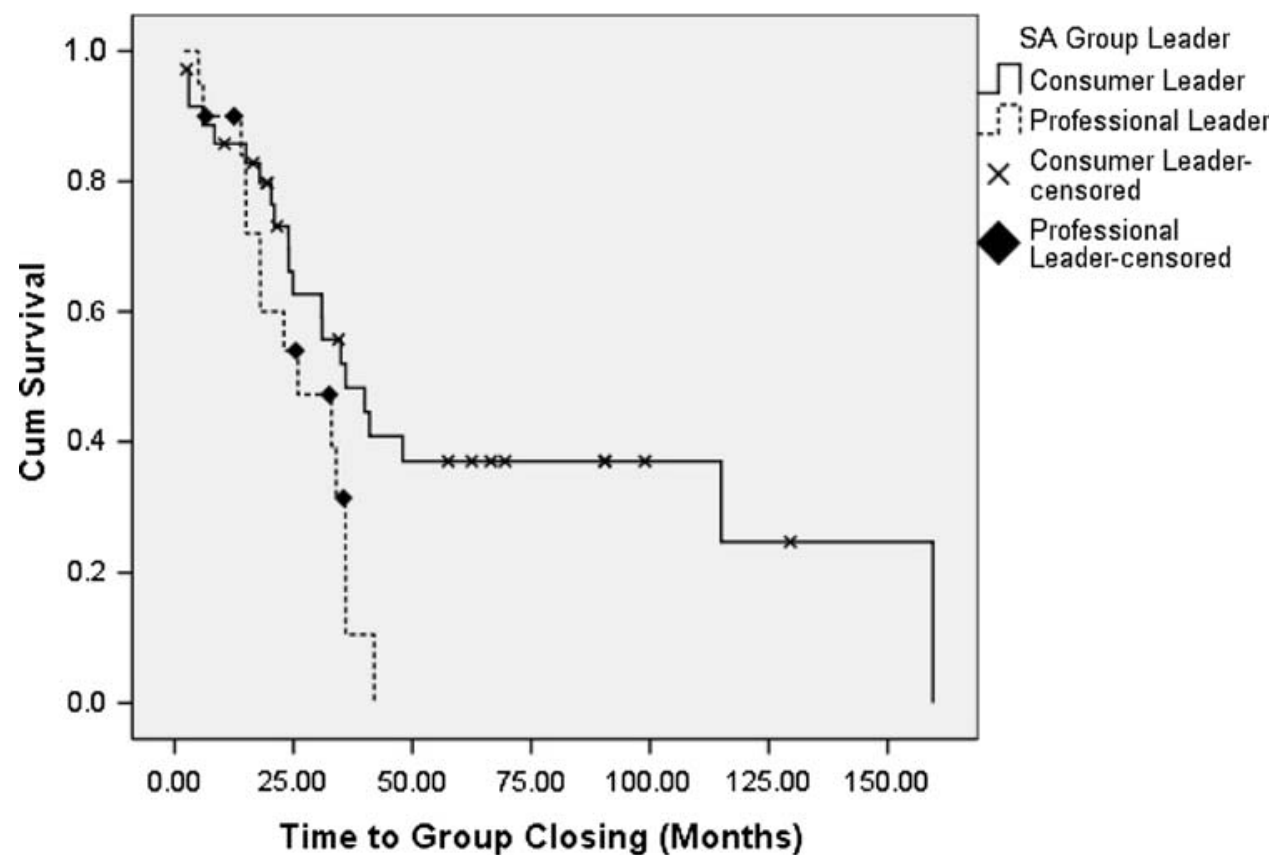

consistency, helping leaders to overcome feelings of discouragement and burnout. As one leader described, "[MHAM staff member] is our guiding light. We rely on him for organizing actual stuff. [I am] glad he is there to help keep it going." Another described her sense of relief in having someone to count on:

There are 2.5 million people [in the U.S.] with schizophrenia and there are so many people out there that need help....And so Bill and I starting thinking...how are we going to distribute? It was just Bill and I mostly... and then Bill got tired. You know, it seemed like it was Bill and I all the time that had all the responsibility. And Ted too...you get burned out. You can't do everything, you know. We gotta have people to take over.

The increased involvement of the MHAM staff member also helped SA to develop a greater administrative capacity.

It was good for the administration of the program because [the MHAM staff member] had administrative skills that I never wanted to have....And it became more of a polished organization because really, we used to laugh...that the organizational file system of SA existed within Joanne's purse....She had, you know, a bunch of stuff in a big purse.... [The MHAM staff member's] contribution pretty early was to develop administrative capacity for SA.

Finally, the involvement of MHAM gave SA greater response capacity. It enabled $\mathrm{SA}$ to respond to the high level of interest and requests for information. During Years
$8-13^{6}$ staff at MHAM provided written responses and/or literature to 752 individuals and organizations in Michigan, the rest of the United States, and around the world. In addition, they answered an untold number of phone inquiries. Schizophrenics Anonymous could never have responded to this level of interest on their own. As one leader said, this would have been particularly true outside of Michigan:

One of [the MHAM staff member's] real accomplishments has been to coordinate the development of the out-of-state groups and include their leaders in a sort of cadre of SA leadership. It's not just a Detroit area thing anymore.

This administrative relief and enhanced capacity to respond to inquiries, however, had associated costs. With the increased leadership role of the MHAM staff member, the leadership role of SA members became less well defined. This was evident in the MHAM staff member's description of the "SA leadership core":

It's never been defined. And it's kind of loose but it's referring to the people that have input or offer input into decisions affecting the program whether it be developing guidelines, you know the group consciousness meeting, and that's probably the closest thing to that leadership core right now. I'd say anybody who has come to a group consciousness meeting is part of that leadership core.

\footnotetext{
${ }^{6}$ InYear 8, MHAM started to keep copies of all correspondence they sent out concerning SA.
} 
Interviews with other SA organizational leaders revealed mixed feelings about MHAM's increasing responsibility for managing SA's development. Leaders expressed concerns about: (a) the more formal, hierarchical structure of SA, (b) decreased consumer control, (c) increased professional involvement, and (d) too much focus on group development and not enough on supporting existing groups. One leader described the changes in idealism he experienced as SA grew more formalized.

I was worried it was getting too big time... I was concerned, there was kind of a group [who] were kind of pining for the early days, I guess. Kind of, there was less, maybe it was less polished, still more of that old idealism.

Another leader noted his relief after giving up a paid position working for MHAM to support SA, "I feel a lot better, more like the old idealism, now that I'm not getting a paycheck."

Leaders also observed decreased consumer control and increased professional involvement in SA. One leader noted a loss of control and ownership:

The group consciousness meeting was nothing but [the MHAM staff member] reporting to the rest of us what he's doing and what he's going to do. There's no real involvement....I wonder why I go sometimes. Sometimes I'm angry when I leave the meetings....I try to go because I want to be involved and I'm interested. But then when I leave, I think what did I come here for?

Some leaders linked the changes to decreased member leadership:

When we got together and wrote that blue book and nobody from MHAM helped us with that except for funding. You know. And there was a big group of people working on it. I mean, right now there's very few people [involved].

Another raised the question, "After 11 years, Joanne should have an entourage of recovered schizophrenics willing to help and do what, like Sara is. Why after 11 years isn't there more Saras willing to help? I don't understand."

A third leader was concerned about the increased professional presence in SA:

[The MHAM staff member] likes to deal with professionals. And this is supposed to be a self-help, support group and professionals have never had the illness and the grass roots, the consumers are the ones that should be starting groups and leading them.
Finally, leaders expressed their concern about focusing too much on group development and not enough on supporting existing groups:

In a relatively short period of time, we doubled the number of groups in Michigan....I had a feeling...you should really be focusing on, really beefing up, the groups that already exist and as these groups would begin to flourish...then the word would get around and groups would just be all over the place.... I was really interested in what's happening to the people who are in the groups right now.

While leaders focused on different aspects of the changes in SA, all recognized a less collective, consumer controlled organization. Most saw both costs and benefits to the partnership.

\section{Reciprocal Influences on MHAM}

Based on interviews with the executive director and staff member at MHAM we identified key ways that the partnership had influenced both the internal functioning and external perception of MHAM. Internally, the partnership assisted MHAM in working towards its' own mission of wellness promotion for persons with mental illness by increasing consumer access to SA. In addition, MHAM began to view consumers as resources for promoting MHAM's mission. The Mental Health Association in Michigan became more attuned to consumer issues and needs and developed increased roles for consumers within MHAM (e.g., serving on board of directors, public speaking, legislative activities). Finally, the grant funding generated by the partnership helped to support the internal operations of MHAM.

The partnership also influenced MHAM's relationship with external organizations. It increased MHAM's external visibility, credibility, and influence. Staff reported that the partnership increased MHAM's visibility in communities throughout Michigan and with the National Mental Health Association. It improved their relationship with other consumer run organizations and with all levels of the mental health system in Michigan. In addition MHAM's access to external funding increased because their role supporting SA made them eligible for service delivery funds.

\section{Discussion}

Following their increased partnership with MHAM, SA underwent significant changes with regard to how new groups were established and how it functioned as an organization. It was difficult to isolate the impact of the 
partnership from other organizational decisions and processes with the methods employed in this study. Schizophrenics Anonymous had already started the process of expanding before the increased involvement of MHAM, as evidenced by the increased effort to develop new groups, leadership structures, and organizational literature. Growth and changes in SA's organizational structure and processes likely would have occurred even if MHAM had not become more involved. However, because MHAM had a more bureaucratic structure, a history of connection with the traditional mental health system, and was positioned to solicit grant funding, it is likely that the types of changes we observed in SA were influenced by its close association with MHAM. The views of the SA leadership further corroborated this perspective, increasing our confidence that the differences in structure, organizational sector, and perspective of these two organizations were influential in just how SA expanded and developed following the formalized partnership. Nevertheless, we acknowledge our limits in drawing strong causal conclusions about the impact of SA's partnership with MHAM.

\section{Changes in How New SA Groups were Established}

Following the development of a more formal partnership, the rate of growth of SA groups increased rapidly and the accessibility of SA to persons in Michigan increased dramatically. The manner in which new groups were started changed as well, with new SA groups more likely to be started in settings controlled by mental health service providers and with professional leaders. While many new SA groups were established using this new strategy, the majority of these groups eventually closed, most during their first three years. Groups appear to need strong leadership and outside support during this critical start-up period.

Our findings suggest that effective group leadership may best come from consumers, rather than professionals. Groups with professional leadership involvement had significantly lower survival times than groups led by consumers. This finding is consistent with Maton et al.'s (1989) finding that for affiliated mutual-help groups, professional involvement was related to higher closure rates. Professional leadership may lead to shorter group survival rates by decreasing the sense of member ownership. As consumer advocates have argued, the presence of professionals decreases consumer choice and control (Chamberlin 1990; Zinman 1987), making it unlikely that consumers will move into leadership positions. This is likely exacerbated by the fact that professional leadership changes the type of expertise valued in a setting (Powell 1990). The experiential knowledge of members which is valued in mutual-help groups (Salem et al. 2000), is not as highly valued by professionals.

\section{Changes in Organizational Processes}

Following the increased partnership with MHAM, SA moved rapidly from the collectivity to the formalization and control stage of development (Quinn and Cameron 1983). While most SA leaders acknowledged the advantages of this development for SA's viability and expansion, some expressed a sense of disenfranchisement; they felt that their own role and the role of other consumers was diminished. In spite of MHAM's efforts to do so, it was difficult to maintain and develop internal leadership in the face of rapid expansion and organizational change.

There are several possible explanations for this. The presence of professional staff and resources may decrease the motivational press for involvement that occurs in under-populated settings. The lack of sufficient people to do the needed work can act as a mechanism of empowerment in mutual-help settings, motivating members to take on new roles and develop new skills (Rappaport, Reischl, and Zimmerman 1992). While professional assistance may relieve stress and prevent burnout, it may also decrease the press for this type of leadership engagement among consumers.

Institutional theory offers a potential system level explanation for our observations. It posits that organizations come to look like other organizations that they associate with because they are rewarded for doing so with increased resources, legitimacy, and viability (Meyer and Rowan 1977; Scott 1995). On their own mutual-help organizations may be highly permeable and supportive training grounds for leadership development. As mutualhelp organizations became more hierarchically structured, there are likely to be fewer of the meaningful role opportunities that characterize empowering settings (Maton and Salem 1995). The addition of paid positions for consumers, while intended to recognize and solidify their leadership role, may in fact decrease the overall permeability of mutual-help organizations and make it more difficult for members and leaders to contribute to group and organizational leadership responsibilities.

\section{Conclusions}

Schizophrenics Anonymous clearly benefited from its partnership with MHAM. It enabled SA to fulfill a primary mission of most mutual-help groups- reaching out to others in need. This capacity had costs for the organization however; the greatest appears to have been a loss of consumer leadership development. Organizational leaders found themselves less sure of their role and somewhat alienated by the changes. Also, more SA groups were led by professional leaders or by consumers who were not 
connected to the training, support, and socialization of Central SA.

The importance of consumer leadership in a mutual-help organization cannot be underestimated. The unique characteristics of mutual-help, including the helper therapy principle (Riessman 1965), experiential knowledge (Borkman 1976), and the availability of meaningful role opportunities (Weaver-Randall and Salem 2004) are made possible because consumers define the community narrative of these settings (Rappaport 1993). As interaction with traditional settings increases, these alternative processes and structures are at risk. In order for mutual-help organizations to maintain their own character when interacting with other types of organizations and systems, they must be conscious not only of their own beliefs and values, but of how these beliefs and values are manifest in their particular organization. Attention must be paid to maintaining not just desired outcomes (e.g., consumer empowerment, recovery) of group involvement but also of the structures and processes that make these outcomes possible.

Schizophrenics Anonymous and MHAM did many things right in this regard. They recognized the importance of maintaining consumer control of the SA program. They were also open to external evaluation of the intended and unintended consequences of their partnership and to implementing changes in response to the results. Although MHAM did not enter the partnership with the expectation that it would strengthen their organization, the fact that it positively influenced MHAM's consumer involvement, visibility, and access to resources facilitated the development of the partnership. The story of SA's relationship with MHAM has continued to be one of increasing cooperation and involvement. In order to more effectively respond to the increasing demands for assistance with SA groups, the National Schizophrenia Foundation (NSF) was formed to assume the MHAM's support functions. This nonprofit organization is dedicated to supporting SA and to public awareness/anti-stigma activities regarding schizophrenia. If this partnership is to continue to be mutually beneficial, it is vitally important that the issues of group sustainability and of consumer involvement and control continue to be addressed.

While most mutual-help organizations are likely to value their independence, professional involvement and collaboration with formal service delivery systems has become a reality for many of these organizations. It is important for mutual-help organization leaders and professional partners to recognize that, even in the most favorable circumstances, close collaboration is likely to lead to change in the unique structures and processes of mutual-help groups. Researchers can help by conducting longitudinal studies that identify mechanisms by which mutual-help organizations effectively decouple key elements from conflicting influences (Oliver 1991) and make decisions that protect their unique qualities (Salem et al. 2002). Such studies are needed if mutual-help organizations wish to interact closely with other systems and organizations without giving up the qualities that make them unique and effective for their members.

Acknowledgements The authors wish to express our appreciation to Joanne Verbanic, Eric Hufnagel, the Mental Health Association in Michigan, The National Schizophrenia Foundation, and the leaders and members of SA who contributed to this study. We would also like to thank Fiona Gallacher who assisted in data collection and Doug Luke for assistance with data analysis. This research was supported in part by a grant from the Ethel and James Flinn Family Foundation.

\section{References}

Bargal, D. (1992). The early stage of the creation of two self-help organizations: An exploratory study. Administration in Social Work, 16(3/4), 81-98.

Ben-Ari, A. T. (2002). Dimensions and predictions of professional involvement in self-help groups: A view from within. Health and Social Work, 27, 95-103.

Borkman, T. J. (1976). Experiential knowledge: A new concept for the analysis of self-help groups. Social Science Review, 50, 445456.

Borkman, T. J. (1999). Understanding self-help/mutual aid. New Brunswick, NJ: Rutgers University Press.

Chamberlin, J. (1990). The ex-patients' movement: Where we've been and where we are going. Journal of Mind and Behavior, 11, 323-336.

Cherniss, C., \& Cherniss, D. S. (1987). Professional involvement in self-help groups for parents of high-risk newborns. American Journal of Community Psychology, 15, 435-444.

Chinman, M., Kloos, B., O’Connell, M., \& Davidson, L. (2002). Service provider's views of psychiatric mutual support groups. Journal of Community Psychology, 30, 349-366.

Comstock, C. M., \& Mohamoud, J. L. (1990). Professionally facilitated self-help groups: Benefits for professionals and members. In T. Powell (Ed.), Working with self-help (pp. 177188). Silver Spring, MD: NASW Press.

DiMaggio, P. J., \& Powell, W. W. (1983). The iron cage revisited: Institutional isomorphism and collective rationality in organizational fields. American Sociology Review, 48, 147-160.

Emerick, R. E. (1991). The politics of psychiatric self-help: Political factions, interactions, support, and group longevity in a social movement. Social Science and Medicine, 32, 1121-1128.

Gartner, A. (1997). Professionals and self-help: The uses of creative tension. Social Policy, 27(3), 47-52.

Gidron, B., \& Hasenfeld, Y. (1994). Human service organizations and self-help groups: Can they collaborate? Nonprofit Management and Leadership, 5, 159-172.

Hasenfeld, Y., \& Gidron, B. (1993). Self-help groups and human service organizations: An interorganizational perspective. Social Service Review, 67, 217-235.

Kaplan, E. L., \& Meier, P. (1958). Nonparametric estimation from incomplete observations. Journal of the American Statistical Association, 53, 457-481.

Kurtz, L. (1990). The self-help movement: Review of the past decade of research. Social Work with Groups, 13(3), 101-115.

Kurtz, L. F., Mann, K. B., \& Chambon, A. (1987). Linking between social workers and mental health mutual-aid groups. Social Work in Heath Care, 13, 69-78. 
Lotery, J. L., \& Jacobs, M. K. (1994). The involvement of self-help groups with mental health and medical professionals: The selfhelpers' perspective. In F. Lavoie, T. Borkman, \& B. Gidron (Eds.), Self-help and mutual aid groups: International and multicultural perspectives (pp. 279-302). Binghamton, NY: Haworth Press.

Luke, D. A. (1993). Charting the process of change: A primer on survival analysis. American Journal of Community Psychology, $21,203-246$.

Mantel, N. (1966). Evaluation of survival data and two new rank order statistics arising in its consideration. Cancer Chemotherapy Reports, 50, 163-170.

Maton, K. I., Leventhal, G. S., Madara, E. J., \& Julien, M. (1989). Factors affecting the birth and death of mutual-help groups: The role of national affiliation, professional involvement, and member focal problem. American Journal of Community Psychology, 17, 643-671.

Maton, K. I., \& Salem, D. A. (1995). Organizational characteristics of empowering community settings: A multiple case study approach. American Journal of Community Psychology, 23, 631-656.

Medvene, L. (1984). Self-help and professional collaboration. Social Policy, 14(4), 15-18.

Meissen, G. J., Mason, W. C., \& Gleason, D. F. (1991). Understanding the attitudes and intentions of future professionals toward self-help. American Journal of Community Psychology, 19, 699714.

Meyer, J. W., \& Rowan, B. (1977). Institutional organizations: Formal structure of myth and ceremony. American Journal of Sociology, 83, 340-363.

Oliver, C. (1991). Strategic response to institutional processes. Academy of Management Review, 16, 145-179.

Olson, B. D., Jason, L. A., Ferrari, J. R., \& Hutcheson, T. D. (2005). Bridging professional and mutual-help: An application of the transtheoretical model to the mutual-help organization. Applied and Preventive Psychology, 11, 167-178.

Patton, M. Q. (2002). Qualitative research and evaluation methods (3rd ed.). Thousand Oaks, CA: Sage Publications.

Pfeffer, J., \& Salanick, G. R. (1978). The external control of organizations. New York: Harper Collins.

Powell, T. J. (1990). Self-help, professional help, and informal help: Competing or complementary systems? In T. J. Powell (Ed.), Working with self-help. Silver Spring, MD: NASW Press.

Powell, T. J., \& Cameron, M. J. (1991). Self-help research and the public mental health system. American Journal of Community Psychology, 19, 797-805.

Quinn, R. E., \& Cameron, K. (1983). Organizational life cycles and shifting criteria of effectiveness: Some preliminary evidence. Management Science, 29, 33-51.

Rappaport, J. (1993). Narrative stories, personal stories, and identity transformation in the mutual help context. Journal of Applied Behavioral Science, 29, 239-236.

Rappaport, J., Reischl, T. M., \& Zimmerman, M. A. (1992). Empowerment mechanisms in the empowerment of former mental patients. In D. Saleebey (Ed.), The strengths perspective in social work practice (pp. 84-97). New York: Longman.

Riessman, F. (1965). The 'helper' therapy principle. Social Work, 10, $27-32$.

Riessman, F., \& Carroll, D. (1995). Redefining self-help: Policy and practice. San Francisco: Jossey-Bass.

Salem, D. A. (1996). Book review: Self help in America: A Social Movement Perspective. Health Education Quarterly, 23, 116119.

Salem, D. A., Foster-Fishman, P. G., \& Goodkind, J. R. (2002). Adoption of innovation in collective advocacy organizations. American Journal of Community Psychology, 30, 681-710.

Salem, D. A., Gant, L., \& Campbell, R. (1998). The introduction of mutual-help groups in group homes for the mentally ill: Barriers to participation. Community Mental Health Journal, 34, 419429.

Salem, D. A., Reischl, T. M., Gallacher, F., \& Randall, K. W. (2000). The role of referent and expert power in mutual help. American Journal of Community Psychology, 28, 303-324.

Schizophrenics Anonymous. (1992). Schizophrenics Anonymous: A self-help support group. Southfield, MI: Mental Health Association in Michigan.

Schubert, M. A., \& Borkman, T. J. (1991). An organizational typology for self-help groups. American Journal of Community Psychology, 19, 769-788.

Scott, W. R. (1995). Institutions and organizations. Thousand Oaks, CA: Sage.

Shepherd, M. D., Schoenberg, M., Slavich, S., Wituk, S., Warren, M., \& Meissen, G. (1999). Continuum of professional involvement in self-help groups. Journal of Community Psychology, 27, 3953.

Stewart, M. (1990). Professional interface with self-help mutual aid groups. Social Science and Medicine, 31, 1143-1158.

Stewart, M., Banks, S., Crossman, D., \& Poel, D. (1994). Partnerships between health professionals and self-help groups: Meanings and mechanisms. In F. Lavoie, T. Borkman \& B. Gidron (Eds.), Selfhelp and mutual aid groups: International and multicultural perspectives (pp. 199-240). New York: The Hawthorne Press.

Toro, P. A., Reischl, T. M., Zimmerman, M. A., Rappaport, J., Seidman, E., Luke, D. A., et al. (1988). Professionals in mutual help groups: Impact on social climate and members' behavior. Journal of Consulting and Clinical Psychology, 56, 631-632.

Weaver-Randall, K., \& Salem, D. A. (2004). Mutual-help groups and recovery: How settings influence participants' experience of recovery. In P. W. Corrigan \& R. O. Ralph (Eds.), Recovery and mental illness: consumer visions and research paradigms. Washington, DC: American Psychological Association Press.

Yoak, M., \& Chessler, M. (1985). Alternative professional roles in health care delivery: Leadership patterns in self-help groups. Journal of Applied Behavioral Science, 21, 427-444.

Zinman, S. (1987). Is the "partnership model" self help? In S. Budd, H. T. Harp, \& S. Zinman (Eds.), Reaching across: Mental health clients helping each other (pp. 16-18). Riverside, CA: California Network of Mental Health Clients. 